\title{
Identification of South African Bermudagrass Germplasm with Shade Tolerance
}

\author{
Jeffrey C. Dunne \\ Department of Crop Science, North Carolina State University, Box 7620, \\ Raleigh, NC 27695-7620
}

\author{
W. Casey Reynolds \\ Department of Soil \& Crop Sciences, Texas A\&M University 2474, College \\ Station, TX 77843-2474
}

\author{
Grady L. Miller \\ Department of Crop Science, North Carolina State University, Box 7620, \\ Raleigh, NC 27695-7620
}

Consuelo Arellano

Department of Statistics, North Carolina State University, Box 8203, Raleigh, NC 27695-8203

\author{
Rick L. Brandenburg \\ Department of Entomology, North Carolina State University, Box 7613, \\ Raleigh, NC 27695-7613
}

\author{
A. Schoeman \\ Sportsturf Solutions, Pretoria, South Africa
}

Fred H. Yelverton and Susana R. Milla-Lewis ${ }^{1}$

Department of Crop Science, North Carolina State University, Box 7620 , Raleigh, NC 27695-7620

Additional index words. accessions, cultivar, bermudagrass, breeding, shade, fertility

\begin{abstract}
Bermudagrass, Cynodon spp. is one of the most commonly grown turfgrass genera in the southern United States having excellent drought tolerance, but poor tolerance to shade. Developing cultivars tolerant to shade would allow bermudagrass to become more prevalent in home lawns or other recreational areas in the southeast, where trees dominate the landscape. In this field study, nine accessions collected from Pretoria, South Africa were evaluated for their ability to grow under shade with varying fertility treatments. These accessions and cultivars 'Celebration', 'TifGrand', and 'Tifway' were evaluated under $0 \%, 63 \%$, and $80 \%$ continuous shade during 2011-12. For both years, significant differences among shade levels, genotypes, and the interaction of the two were observed. As expected, the progression from $0 \%$ to $63 \%$ to $80 \%$ shade reduced normalized difference vegetation index (NDVI), percent turfgrass cover (TC), and turf quality (TQ) readings for all accessions. Some genotypes, however, were able to maintain adequate quality and aggressiveness under 63\% shade. 'Celebration', WIN10F, and STIL03 performed better than 'Tifway' $(P \leq 0.05)$, the susceptible control. Overall, our results indicate that there are promising genotypes among the bermudagrass materials collected from South Africa. These accessions represent additional sources of shade hardiness to be used in bermudagrass breeding. Furthermore, higher nitrogen fertility provided increased NDVI and TQ in some instances suggesting an added benefit of fertility under low-light conditions. However, the increased economic value attributed to the added inputs associated with these increases is outweighed by the low impacts offered.
\end{abstract}

The growth characteristics of bermudagrass (Cynodon spp.) promote its use across

\footnotetext{
Received for publication 2 Apr. 2015. Accepted for publication 28 July 2015.

This research was supported in part by the North Carolina Crop Improvement Association and the Center for Turfgrass Environmental Research and Education at North Carolina State University. ${ }^{1}$ Corresponding author. E-mail: susana_milla-lewis@ ncsu.edu.
}

a wide range of environments. Its aggressive behavior, resistance to weed encroachment, traffic tolerance, and drought tolerance makes bermudagrass a desired species on golf courses, athletic fields, municipalities, and home lawns in North Carolina (Carrow and Petrovic, 1992; DiPaola and Beard, 1992 ). However, it is estimated that $20 \%$ to $25 \%$ of all turfgrass stands are under some kind of shade, primarily from trees and/or other structural objects (Beard, 1973) and of the warm-season turfgrasses typically used in the south, bermudagrass exhibits the poorest shade tolerance (Dudeck and Peacock, 1992).

The effects of shade can elicit profound physiological, morphological, and field performance effects on turfgrasses. McBee and Holt (1966) originally showed that decreases in light incidence drastically reduced percent TC, density, and color of bermudagrass. Schmidt and Blaser (1969) evaluated the effects of temperature, light, and nitrogen on growth and metabolism of 'Tifgreen' [Cynodon dactylon (L.) Pers. $\times$ C. transvaalensis Burtt Davy] bermudagrass. The results of their experiment suggested that low light intensity drastically inhibited nitrogen utilization for shoot growth and root development. Overall, the effects of shade can reduce TQ, turfgrass density, NDVI, chlorophyll content, root mass, pigment concentrations, total nonstructural carbohydrates, petiole length, internode diameter, number of stolons, total stolon lengths, and canopy photosynthetic rates (Baldwin et al., 2008; Bell and Danneberger, 1999b; Bunnell et al., 2005a; Peacock and Dudeck, 1981; Qian and Engelke, 1997; Sladek et al., 2009; Stuefer and Huber, 1998; Van Huylenbroeck and Van Bockstaele, 2001; Stuefer and Huber, 1998).

For breeding programs, turfgrass cultivars, and novel turfgrass accessions must be evaluated to improve on specific traits. Typically, these collections are subjected to rigorous selection pressure. Research to evaluate turfgrasses for shade tolerance has often used artificial shade to mimic environmental conditions (McBee and Holt, 1966; Peacock and Dudeck, 1981; Qian and Engelke, 1997; Sladek et al., 2009; Trenholm and Nagata, 2005; Van Huylenbroeck and Van Brockstaele, 2001; Wilkinson and Beard, 1975). Many forms of artificial shade have emerged for properly evaluating the trait. Baldwin et al. (2009) used various colors of shadecloth $(65 \%$ light reduction in all treatments) to filterspecific wavelengths to determine their individual effects on TQ, relative clipping yield, relative chlorophyll concentration, relative shoot width, relative root biomass, relative root length density, relative specific root length, and root and shoot total nonstructural carbohydrates in bermudagrass. While each of the colored shade fabrics reduced specific measures, the black shadecloth provided the most detrimental effect across all response parameters. Varying levels of photosynthetic photon flux $(P P F)$ allow for estimation of thresholds for acceptable TQ within turfgrass entries (Bunnell et al., 2005a; McBee and Holt, 1966; Miller et al., 2005; Sladek et al., 2009; Trenholm and Nagata, 2005; Van Huylenbroeck and Van Brockstaele, 2001).

Research has shown significant variation among bermudagrass genotypes in shade response. Under $90 \%$ uninterrupted shade, Gaussoin et al. (1988) noted the diversity in shade tolerance among 32 bermudagrass genotypes. Similarly, Baldwin et al. (2008) evaluated 42 bermudagrass cultivars 
collected from the National Turfgrass Evaluation Program (NTEP) and were able to group them into distinct classes (best, intermediate, and sensitive) based on TQ, shoot chlorophyll concentration, root length, and total root biomass. Finally, Hanna et al. (2010) evaluated the newly registered 'ST-5' [Cynodon dactylon (L.) Pers. $\times C$. transvaalensis Burtt Davy] bermudagrass cultivar (later released as 'TifGrand'-PP21017; Hanna and Braman, 2008) against other dwarf-type bermudagrass cultivars and showed 2-fold increases in TC under $70 \%$ continual shade.

Bermudagrass materials are often compared against other species to evaluate shade tolerance. Jiang et al. (2004) compared two hybrid bermudagrass cultivars to eight seashore paspalum cultivars and showed the bermudagrass hybrids maintained the lowest TQ throughout the study. However, Bunnell et al. (2005a) and Baldwin et al. (2009) showed recent gains in bermudagrass shade tolerance through the release of 'Celebration' (Riley, 2000), a common-type [Cynodon dactylon (L.) Pers.]. In the two studies, 'Celebration' exhibited superior shade tolerance compared with bermudagrass hybrids and performed similarly to 'Sea Isle 2000' seashore paspalum (Paspalum vaginatum Swartz.).

In addition to cultivar development through breeding and selection, further improvement in warm season turfgrass response to shade can be attained through cultural practices. Previous research suggests that reducing nitrogen fertility rates (Bell and Danneberger, 1999a; Bunnell et al., 2005b; Goss et al., 2002) and raising mowing heights (Bunnell et al., 2005b; Bell and Danneberger, 1999a; White, 2004) can improve TQ and overall turfgrass performance under lowlight conditions.

The development of shade-tolerant cultivars, specifically TifGrand and 'Celebration', has shown the potential of bermudagrass to persist in low-light environments. However, with only these two commercially available shade-tolerant cultivars, there is great need for introducing new germplasm or cultivars with further enhanced shade tolerance. This should be possible through identification of new shade tolerance sources and breeding efforts. In the early 1990s, a collection trip to South Africa resulted in the introduction of nine common bermudagrass [Cynodon dactylon (L.) Pers.] accessions that showed promising shade tolerance in their native environment. The objectives of this research were to evaluate these accessions for shade tolerance under varying levels of $P P F$, and to estimate the effect of nitrogen fertilization on the performance of these materials under shade.

\section{Materials and Methods}

Plot establishment and management. A 2-year evaluation was conducted between 16 Aug. and 29 Sept. in 2011 and between 2 Aug. and 11 Sept. in 2012 at the Lake
Wheeler Turfgrass Experimental Field Laboratory in Raleigh, $\mathrm{NC}\left(37^{\circ} \mathrm{N}\right.$ lat.; $78^{\circ} \mathrm{W}$ long.). Plots, $4.65 \mathrm{~m}^{2}(1.5 \times 3.1 \mathrm{~m})$ in size, of the selected bermudagrass entries (Table 1) were established from sod in early fall of 2010 on an Appling fine sandy loam/Cecil sandy loam (fine, kaolinitic, thermic Typic Kanhapludults) (NRCS, 2011).

A granular diammonium phosphate $(18 \mathrm{~N}-20 \mathrm{P}-0 \mathrm{~K})$ fertilizer (Southern Seeds, Inc.; Middlesex, NC) was applied at a nitrogen rate of $48.8 \mathrm{~kg} \cdot \mathrm{ha}^{-1}$ during establishment in 2010 and then again on 24 June 2011 before the initiation of fertility treatments. Irrigation was applied immediately after each application. Each of the designated shade treatment areas was established under full sunlight until the shade treatments were applied 2 July 2011. The shadecloth was not removed for the duration of the study. From the initiation to the completion of the research, all plots were maintained once per week at a $5.1 \mathrm{~cm}$ mowing height with a rotary mower and irrigation was applied as needed to prevent drought stress. Clippings were returned to the plots during each mowing event.

Factors and factor levels. The study was established as a nested split-split plot design with the main plot factor being various levels of shade. The shade levels were $0 \%, 63 \%$, and $80 \%$ shade allowing $100 \%, 37 \%$, and $20 \%$ of full sunlight, respectively. Shade treatments (other than full sunlight) were applied using a neutral density, polyfiber black shadecloth (Long's Greenhouse Enterprise, Inc. Jacksonville, FL) on a perpetual basis by constructing a shade structure surrounding the established plots. Percent shade was determined by the installation contractor comparing $P P F$ under shade cloths at the turfgrass canopy to full sunlight measurements with a hand-held LI-190SA quantum sensor (LI-COR, Lincoln, NE). Three replications of the twelve entries were organized in complete blocks, nested within each shade treatment. Of the twelve entries, nine were a collection of accessions from the Pretoria region in South Africa. All accessions were common-type bermudagrasses [C. dactylon (L.) Pers.]. Two positive controls, 'Celebration' and 'TifGrand', were used based on previous studies suggesting their relative shade hardiness among bermudagrasses

Table 1. List of bermudagrass genotypes evaluated for shade tolerance under $0 \%, 63 \%$, and $80 \%$ shade for 2 years (2011-12) at the Lake Wheeler Turfgrass Field Laboratory, Raleigh, NC.

\begin{tabular}{lll}
\hline Entry & \multicolumn{1}{c}{ Type } \\
'Celebration' & Shade-tolerant cultivar & \multicolumn{1}{c}{ Cynodon dactylon (L.) Pers. } \\
CoPCCQ & Collection & Cynodon dactylon (L.) Pers. \\
FiPCCQ & Collection & Cynodon dactylon (L.) Pers. \\
Irene & Collection & Cynodon dactylon (L.) Pers. \\
PCC4 & Collection & Cynodon dactylon (L.) Pers. \\
PCCT & Collection & Cynodon dactylon (L.) Pers. \\
STIL03 & Collection & Cynodon dactylon (L.) Pers. \\
'Tifgrand' & Shade-tolerant cultivar & Cynodon dactylon (L.) Pers. $\times$ C. transvaalensis Burtt Davy \\
'Tifway' & Shade susceptible cultivar & Cynodon dactylon (L.) Pers. $\times$ C. transvaalensis Burtt Davy \\
WIN10F & Collection & Cynodon dactylon (L.) Pers. \\
WIN10T & Collection & Cynodon dactylon (L.) Pers. \\
WIN17 & Collection & Cynodon dactylon (L.) Pers. \\
\hline
\end{tabular}

(Baldwin et al., 2009; Bunnell et al., 2005a; Hanna and Maw, 2007; Hanna et al., 2010). 'Tifway' (Burton, 1966) was used as the susceptible control. Each entry was split into equal plot sizes $(1.5 \times 1.5 \mathrm{~m})$ to accommodate two levels of nitrogen fertilization that were randomly assigned within each plot. One month following the fertilization on 24 June 2011, the split fertility treatments were initiated to provide nitrogen at $97.6 \mathrm{~kg} \cdot \mathrm{ha}^{-1}$ (low) and $195.2 \mathrm{~kg} \cdot \mathrm{ha}^{-1}$ (high) during the data collection period using a granular, polymercoated urea $(18 \mathrm{~N}-4 \mathrm{P}-15 \mathrm{~K})$ fertilizer (Harrell's, Lakeland, FL). The same treatments resumed on 9 July 2012. To achieve the low- and highfertility treatment totals, applications were made at a nitrogen rate of $48.8 \mathrm{~kg} \cdot \mathrm{ha}^{-1}$ either every 4 weeks (high) or every 8 weeks (low) throughout the data collection periods in both years.

Response variables. To measure the tolerance of each entry under the various shade and fertility treatments, percent TC ratings were taken at 3-week intervals following the removal of a golf course cup-cutter sized $\left(86.6 \mathrm{~cm}^{2}\right)$ plug of turf that was back filled with silica sand. Digital images were taken 3 weeks (16 Aug. 2011 and 2 Aug. 2012), 6 weeks (7 Sept. 2011 and 22 Aug. 2012), and 9 weeks (29 Sept. 2011 and 11 Sept. 2012) after plug removal to monitor the regrowth, measured as percent cover, within each treatment. A portable light box was used to provide a consistent light source for capturing images. The images were analyzed using Sigma Scan (Systat Software; Chicago, IL) to determine the ratio of green pixels to total pixels of the cross-sectional area, iteratively (Karcher and Richardson, 2005; Richardson et al., 2001). In addition, NDVI and TQ ratings were taken at each of the indicated time points. NDVI data were recorded as an average of 20 measurements taken across the entirety of each plot. The readings were taken using the Field Scout TCM 500 turf color meter (Spectrum Technologies, Inc., Plainfield, IL). Ratings of visual assessment for TQ were collected on a 1 to 9 scale that combines the turfgrass characteristics of texture, color, density, and uniformity, where a rating of 1 represents inferior, 9 represents superior, and 6 represents acceptable TQ (NTEP, 2012). TQ ratings are representative of the entire plot area. 
Statistical analysis. Initial attempts to fit the data were performed spatially to take advantage of the possible variation patterns within the field. However, difficulties converging the model were encountered due to increased variability observed from 2011 to 2012. Therefore, the data were modeled based on the experimental design and each of the factor effects and interactions were tested against the appropriate error term determined by their expected mean squares (Table 2). Furthermore, due to the continuation of the shade treatments, differences in rating times, and the variability observed between years, the data were analyzed more parsimoniously by date using the generalized linear model (GLM) procedure in SAS version 9.4 (SAS Institute Inc., 2005). Individual hypothesis testing of effects and interactions was designated using an appropriate error term which is available in the GLM procedure. Mean separation procedures were used when appropriate according to Fisher's protected least significant difference values at a significance level of 0.05 . Again, appropriate error terms were used during the mean separation procedure to determine significance between treatments.

Because of the quantitative nature of the shade treatments and the unequal spacing in the shade increments, orthogonal polynomials were designed according to Robson (1959) to test linear and deviations from linear (potential quadratic characteristics) of the increasing shade treatments. To address the performance of the entries across years, additional contrasts were designed to test each of the entries against the average of the remaining entries, within shade levels, on each date. The effect analysis is similar to the stability analysis conducted by Bokmeyer et al. (2009) comparing tall fescue (Festuca arundinacea Schreb.) clones across environments. In this case, these comparisons were used to easily discern consistency and stability of the entries across years and the response variables, respectively.

\section{Results and Discussion}

Only the data for the final rating date ( 9 weeks after cup-cutter removal) are presented, conveying the results in each year (2011 and 2012). The analysis of variance determined the importance of entry, and the interaction between the entries and shade treatments (Table 1). Due to the significance of the interaction, means separation analysis was conducted for entries within each shade level. Since the study was a 2-year continuous evaluation of the effects of shade on the entries, overall conclusions can be drawn from the results on 11 Sept. 2012. However, the mean results of both years (representing data collected on 29 Sept. 2011 and 11 Sept. 2012 only) for NDVI, TQ and percent TC are presented (Fig. 1; Supplemental Tables 1 and 2).

Full sunlight (0\% shade) treatments. In 2011 (29 Sept. 2011), NDVI values did not differ among the entries under full-light conditions (Fig. 1; Supplemental Table 1, $P \geq$ 0.05). Similarly, for TC, only one entry was significantly different from the rest. The accession PCC4 was lower $(P \leq 0.05)$ than all other entries after the 9 weeks of growth. A wide range in values was shown among entries when considering traits (color, texture, density, and uniformity) that comprise TQ, which was expected given the different backgrounds of the accessions being evaluated. 'TifGrand' showed the highest TQ (8.0), but was not different from accessions Irene $(7.3 ; P=0.223)$ and WIN17 (7.0; $P=0.070)$. The accession PCC4 showed the lowest TQ (4.0) when compared with all other entries $(P \leq 0.05)$.

In 2012 (11 Sept. 2012), plots showed an overall decline in NDVI. Although comparisons between 2011 and 2012 were not directly made in the final analysis as previously mentioned in the Statistical Analysis and Materials and Methods sections, accessions WIN10F, WIN17, Irene, and STIL03 were among the highest in NDVI (Fig. 1; Supplemental Table 2). Similarly, an overall decline in percent TC under full sunlight was noted in the second year of the study. From 2011 to 2012, the estimated decline in the overall mean for percent TC was nearly $25 \%$. WIN10F, WIN17, PCCT and 'WIN10T' were among the highest in percent TC after 9 weeks of growth. Although NDVI and percent TC ratings declined in full sunlight treatments between years, TQ was relatively unaffected. Accessions WIN10F, Irene, and WIN17 were recorded as having the highest TQ. The performance of each genotype under full sunlight is undoubtedly important, but the purpose in evaluating them under full-light conditions was mainly to estimate the effects of the shade treatments on the individual entries.

Sixty-three percent shade treatment. As shade increased to $63 \%$, NDVI values in 2011 declined by $18 \%$ compared with the $0 \%$ shade treatments and displayed a wide range in values among the entries ( 0.675 to 0.358). 'Celebration' had the highest NDVI value. No differences were seen between 'Celebration' and accessions STIL03, WIN10F, PCC4, and CoPCCQ. However, these accessions and 'Celebration' were lower $(P<0.05)$ in NDVI compared with $0 \%$ shade treatment. Percent TC declined by $48 \%$ under $63 \%$ shade compared with full sunlight. 'Celebration' had the highest percent TC after the 9-week period (Fig. 1; Supplemental Table 1). Although lower by $10 \%$ compared with the $0 \%$ shade plots, STIL03 and WIN10F covered nearly $60 \%$ of the cross-sectional area. Similar to the $0 \%$ shade treatment, entries under $63 \%$ shade exhibited a wide range in TQ (3.5 to 6.7) (Fig. 1; Supplemental Table 1). STIL03 and WIN10F differed from 'Celebration', but were similar to 'TifGrand' (Fig. 1; Supplemental Table 1). Furthermore, the two accessions maintained TQ from full sunlight to $63 \%$ shade.

In 2012, differences were evident in NDVI values under the $63 \%$ shade treatment. WIN10F and STIL03 were among the top performing accessions in this category, and were not different from 'Celebration' (Fig. 1; Supplemental Table 2). Unlike the decline experienced in the $0 \%$ shade treatments from 2011 to 2012, treatments under the $63 \%$ shade treatment maintained nearly $50 \%$ TC after 9 weeks of growth. As seen in 2011, STIL03 and WIN10F had similar percent TC to that of 'Celebration'. Furthermore, these two accessions had percent TC similar to each of the top performing entries under $0 \%$ shade. Differences in TQ were seen under $63 \%$ shade in 2012, separating the better performing accessions from the poorer ones (TQ $=6$ or higher; based on acceptable TQ). STIL03 and WIN10F did not differ in TQ to 'Celebration' and were the only South African accessions to exhibit TQ above acceptable levels.

A discernible decline in turfgrass response was observed under $63 \%$ as compared with full sunlight $(P<0.05)$. These results support previous studies (Baldwin et al.,

Table 2. Observed significance for testing null hypothesis of no effects from the analysis of variance for normalized difference vegetation index (NDVI), turfgrass cover and turfgrass uuality from data collected on 29 Sept. 2011 and 11 Sept. 2012 at the Lake Wheeler Turfgrass Field Laboratory, Raleigh, NC. Analysis conducted on the main effects, two-way interactions and three-way interactions of shade, entry, and fertility for each date independently.

\begin{tabular}{|c|c|c|c|c|c|c|c|}
\hline \multirow[b]{2}{*}{ Model source } & \multirow[b]{2}{*}{ DF } & \multicolumn{3}{|c|}{29 Sept. $2011^{z}$} & \multicolumn{3}{|c|}{11 Sept. 2012} \\
\hline & & NDVI & Turfgrass cover $(\%)$ & Turfgrass quality & NDVI & Turfgrass cover $(\%)$ & Turfgrass quality \\
\hline Shade & 2 & $<0.0001$ & $<0.0001$ & $<0.0001$ & $<0.0001$ & $<0.0001$ & $<0.0001$ \\
\hline Block (shade) & 6 & - & - & - & - & - & - \\
\hline Entry & 11 & $<0.0001$ & $<0.0001$ & $<0.0001$ & $<0.0001$ & $<0.0001$ & $<0.0001$ \\
\hline Shade $\times$ entry & 22 & $<0.0001$ & $<0.0001$ & $<0.0001$ & $<0.0001$ & 0.0251 & $<0.0001$ \\
\hline Entry $\times$ block (shade) & 66 & - & - & - & - & - & - \\
\hline Fertility & 1 & 0.0536 & 0.5224 & 0.0781 & 0.0384 & 0.0624 & 0.0037 \\
\hline Shade $\times$ fertility & 2 & 0.3906 & 0.0135 & 0.2963 & 0.5187 & 0.2198 & 0.0787 \\
\hline Fertility $\times$ block (shade) & 6 & - & - & - & - & - & - \\
\hline Entry $\times$ fertility & 11 & 0.2448 & 0.6431 & 0.2482 & 0.6793 & 0.589 & 0.9449 \\
\hline Shade $\times$ entry $\times$ fertility & 22 & 0.1502 & 0.9255 & 0.7423 & 0.488 & 0.5662 & 0.6699 \\
\hline Entry $\times$ fertility $\times$ shade (block) & 66 & - & - & - & - & - & - \\
\hline
\end{tabular}

${ }^{\mathrm{z} D a t e s}$ in both years (2011 and 2012) are 9 weeks after cup-cutter removal. 


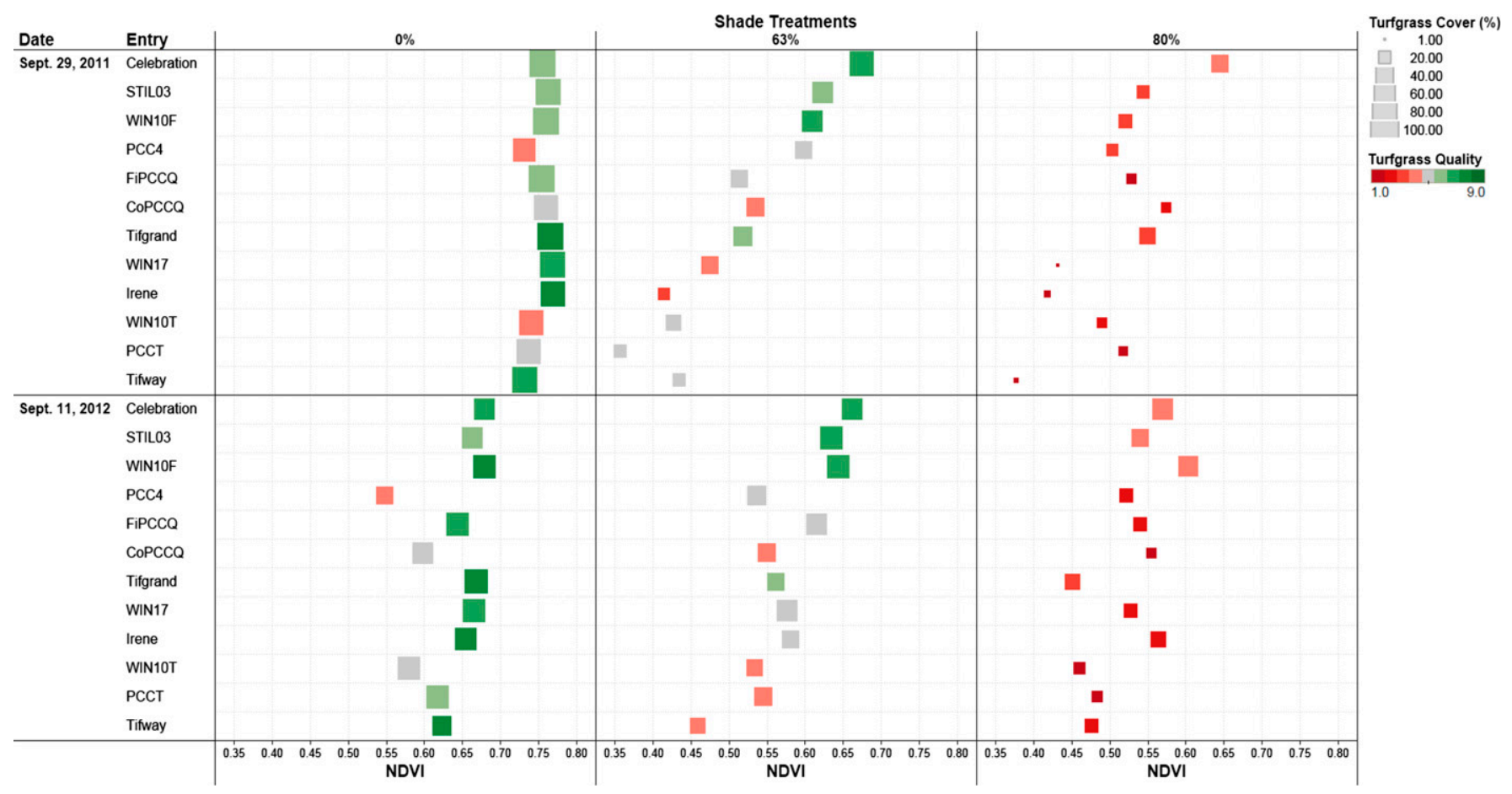

Fig. 1. Normalized difference vegetation index (NDVI) data collected 29 Sept. 2011 and 11 Sept. 2011 at the Lake Wheeler Turfgrass Field Laboratory in Raleigh, NC, visually separating entries within each date and shade level for NDVI, turfgrass cover (TC) and turfgrass quality (TQ). Entries were first separated by NDVI values within shade levels $(0 \%, 63 \%$, and $80 \%)$. To further the separation in entries, varying degrees of marker size were associated to the percent TC taken on the two dates and colors ranging from red to green represent TQ based on the scale in which the data were collected.

2008; Bell and Danneberger, 1999b; Gaussoin et al., 1988; Sladek et al., 2009; Van Huylenbroeck and Van Bockstaele, 2001) that showed reductions in overall turfgrass performance, including TQ and TC, due to perpetual shade coverage at varying light percentages. The $63 \%$ shade treatment provided the best separation of treatments in both years and all response variables collected. The cultivar Celebration and accessions WIN10F and STIL03 were found to provide the greatest shade response in both years (reflective in the consistent performance in NDVI, TC, and TQ in 2011 and 2012). The performance of 'Celebration' was consistent with previous research efforts when compared with 'Tifway' (Baldwin et al., 2008, 2009; Bunnell et al., 2005a). 'TifGrand' did not provide the same level of response compared with these entries in both years, but maintained levels greater to that of 'Tifway' corresponding to previous findings comparing the two (Hanna et al., 2010).

Eighty-percent shade treatment. In 2011, NDVI means across entries for the $80 \%$ and $63 \%$ shade could not be clearly distinguished $(P>0.05)$; however, ranks among entries differed. The accession CoPCCQ was similar in NDVI compared with 'Celebration' and there were no differences between STIL03 and 'TifGrand' or CoPCCQ (Fig. 1; Supplemental Table 1). Furthermore, CoPCCQ and STIL03 had higher NDVI values under $80 \%$ shade

Table 3. Mean separation of fertility treatments for normalized difference vegetation index (NDVI), turfgrass cover and turfgrass quality from data collected on 29 Sept. 2011 and 11 Sept. 2012 at the Lake Wheeler Turfgrass Field Laboratory, Raleigh, NC.

\begin{tabular}{|c|c|c|c|c|c|c|}
\hline \multirow[b]{2}{*}{ Fertility } & \multicolumn{3}{|c|}{29 Sept. $2011^{z}$} & \multicolumn{3}{|c|}{11 Sept. 2012} \\
\hline & NDVI & $\begin{array}{c}\text { Turfgrass } \\
\text { cover }(\%)\end{array}$ & $\begin{array}{c}\text { Turfgrass } \\
\text { quality }\end{array}$ & NDVI & $\begin{array}{l}\text { Turfgrass } \\
\text { cover }(\%)\end{array}$ & $\begin{array}{c}\text { Turfgrass } \\
\text { quality }\end{array}$ \\
\hline High & 0.587 & 47.4 & 4.5 & 0.583 & 48.5 & 4.8 \\
\hline Low & 0.598 & 47.9 & 4.5 & 0.574 & 45.7 & 4.7 \\
\hline Significance & NS & NS & NS & $*$ & NS & $* *$ \\
\hline
\end{tabular}

$*, * *$ denote significance levels of $P=0.05$ and $P=0.01$, respectively.

${ }^{z}$ Dates in both years (2011 and 2012) are 9 weeks after cup-cutter removal.

Table 4. Mean separation for the shade by fertility interaction for normalized difference vegetation index (NDVI), turfgrass cover (TC) and turfgrass quality (TQ) from data collected on 29 Sept. 2011 and 11 Sept. 2012 at the Lake Wheeler Turfgrass Field Laboratory, Raleigh, NC.

\begin{tabular}{|c|c|c|c|c|c|c|c|}
\hline \multirow[b]{2}{*}{ Shade } & \multirow[b]{2}{*}{ Fertility } & \multicolumn{3}{|c|}{29 Sept. $2011^{z}$} & \multicolumn{3}{|c|}{11 Sept. 2012} \\
\hline & & NDVI & TC (\%) & $\overline{T Q}$ & $\overline{\text { NDVI }}$ & TC (\%) & $\overline{T Q}$ \\
\hline $0 \%$ & High & 0.752 & 82.0 & 6.1 & 0.637 & 61.1 & 6.5 \\
\hline $0 \%$ & Low & 0.755 & 81.6 & 6.1 & 0.634 & 61.6 & 6.3 \\
\hline $63 \%$ & High & 0.505 & 40.2 & 5.1 & 0.580 & 51.8 & 5.3 \\
\hline $63 \%$ & Low & 0.526 & 44.7 & 5.1 & 0.571 & 46.5 & 5.2 \\
\hline $80 \%$ & High & 0.503 & 20.0 & 2.3 & 0.531 & 32.4 & 2.6 \\
\hline \multirow[t]{2}{*}{$80 \%$} & Low & 0.515 & 17.2 & 2.3 & 0.518 & 28.9 & 2.5 \\
\hline & $\operatorname{LSD}(P=0.05)$ & $\mathrm{NS}^{\mathrm{y}}$ & 2.93 & NS & NS & NS & NS \\
\hline
\end{tabular}

LSD $=$ least significant difference.

${ }^{z}$ Dates in both years (2011 and 2012) are 9 weeks after cup-cutter removal.

ySignificant means differ by more than LSD value according to Fisher's protected LSD $(P=0.05)$.

than most of the entries (67\%) under the $63 \%$ shade treatment. Likewise, WIN10F under $80 \%$ shade was higher than $58 \%$ of the entries under the $63 \%$ treatment, including 'TifGrand'. Unlike the observations for NDVI, clear separation existed in percent TC between the $63 \%$ and $80 \%$ shade treatments $(P<0.05)$ WIN10F and STIL03 were still among the top performing accessions (Fig. 1; Supplemental Table 1). Following the trends within each of the response variables and shade treatments, WIN10F, STIL03, and PCC4 
performed similar to both of the positive controls ('Celebration' and 'TifGrand') in TQ. Yet, all entries had a TQ value well below the acceptance level.

In 2012, NDVI values did not decline as severely when increasing from $63 \%$ to $80 \%$ shade as seen in 2011 ( $\approx 8 \%$ on average across all entries); however, the rankings of accessions were still altered. WIN10F continued to show the highest NDVI values when compared with the other accessions and had a similar NDVI to that under $63 \%$ shade (Fig. 1; Supplemental Table 2). Irene performed similar to WIN10F. STIL03 declined with the shade increase and was lower than WIN10F $(P=0.014)$, yet remained similar to 'Celebration'. Growth after 9 weeks declined nearly $40 \%$ on average across all entries compared with the $63 \%$ shade treatments. Differences in percent TC were apparent across shade levels and were present in both years with accessions STIL03 and WIN10F having greater cover than the other accessions. Lastly, there were no entries that performed above acceptable values for TQ under $80 \%$ shade in 2012. WIN10F and STIL03 were higher $(P \leq$ $0.05)$ in TQ when compared with each of the accessions (Fig. 1), but no differences were seen between these two accessions and the shade-tolerant cultivar Celebration $(P>0.05)$.

Comparing the levels of light penetrance, the $80 \%$ shade treatment was more devastating to entries than the $63 \%$ treatment, on average, with all entries well below acceptable standards. Mean separation of treatments was not as defined as under the $63 \%$ shade. However, the accessions WIN10F and STIL03 and the cultivar Celebration continued to be aggressive, providing the highest shade performance of the collected accessions suggesting a heightened shade adaptation beyond a $63 \%$ reduction in light.

Fertility. In 2011, only the interaction between shade and fertility was significant for percent TC (Table 1). In the interaction between shade and fertility, the influence of the levels of fertility on shade response changed from $0 \%$ to $63 \%$ and then from $63 \%$ to $80 \%$. Under full sun conditions, the high-fertility treatment was not different with only $0.39 \%$ greater TC (Table 3 ). As shade

$0 \%$ Shade

$63 \%$ Shade

$80 \%$ Shade

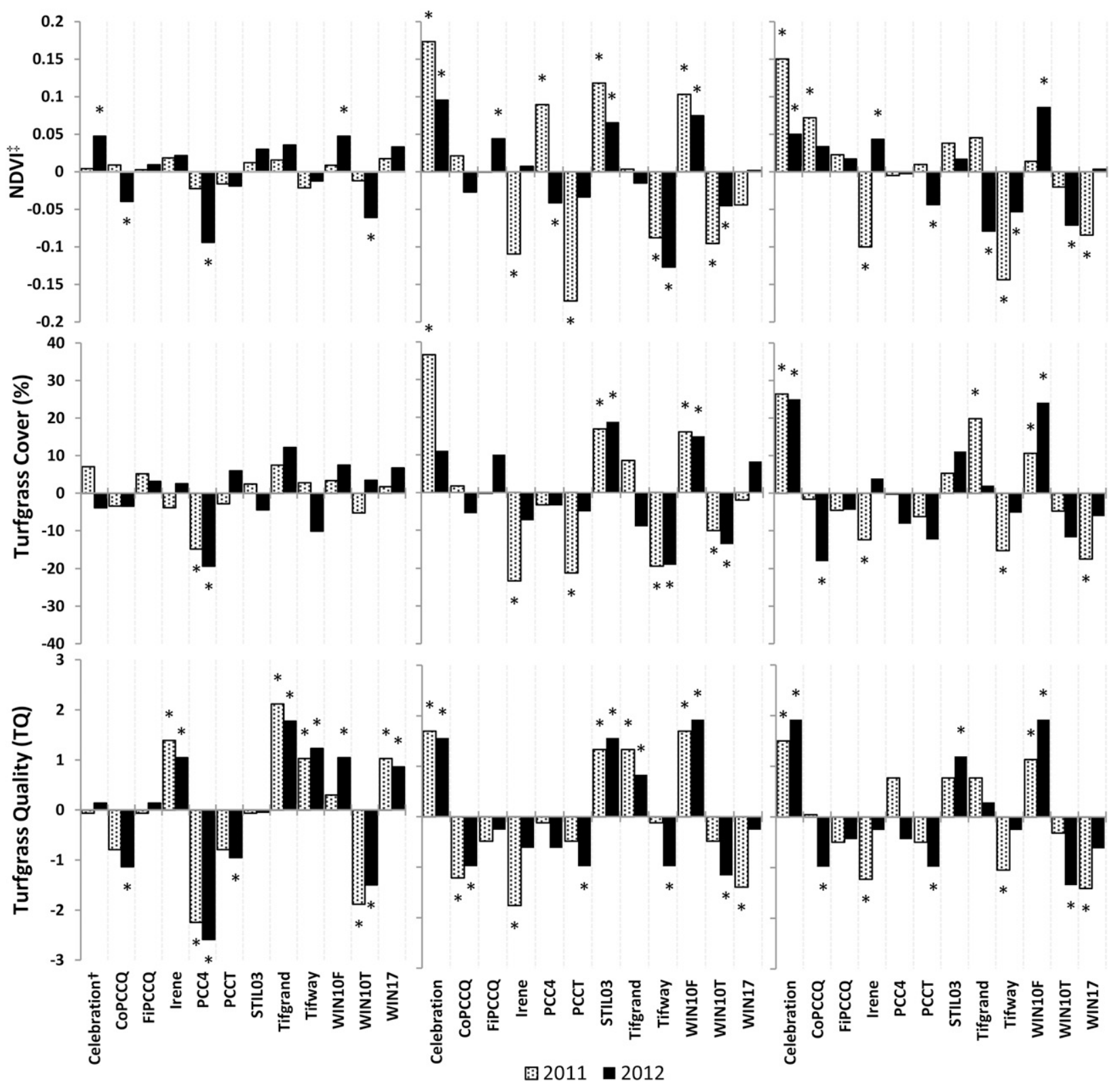

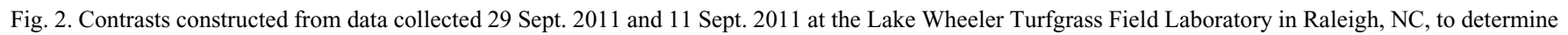
differences between the mean of each individual entry and the mean of all of the other entries developed for within shade and year comparisons for normalized difference vegetation index, Turfgrass cover, and Turfgrass quality. Bars indicate differences between the entry mean and the mean of all other entries. * Significant contrasts between entry mean and mean of all other entries according to $P=0.05$. 
increased from $0 \%$ to $63 \%$, the low-fertility treatment was greater in TC than the high treatment by $4.6 \%$, which was significant $(P \leq 0.05)$. When the shade level increased to $80 \%$, the high-fertility treatment was not statistically different to the low-fertility treatment (Table 3 ).

In 2012, the main effect for fertility was significant for NDVI and TQ (Table 1). Across all of the entries, treatments receiving the highfertility treatment $\left(195.2 \mathrm{~kg} \cdot \mathrm{ha}^{-1}\right)$ had greater NDVI levels (Table 4). However, a difference in treatments of 0.009 in NDVI between fertility treatments suggests a low biological significance between the two treatments. Similarly on this date, higher levels of fertility yielded higher TQ ratings, but again, difference of 0.09 between the high- and low-fertility treatments suggests a low biological significance (Table 4).

In 2011, the variation in the effects of the fertility treatments when compared with previous research conducted on fertility management in shade can be attributed to the inclusion of the $0 \%$ shade treatment in the analysis and the overall decline of the performance of the entries under $80 \%$ shade. The interaction of shade $\times$ fertility for TC in 2011, specifically under $63 \%$ shade, showed parallel findings to previous research conducted on the topic reiterating the need of reduced nitrogen fertility for improved turfgrass management under shade (Bell and Danneberger, 1999a; Bunnell et al., 2005b; Goss et al., 2002). As previously mentioned, in 2012 , the high-fertility treatment showed higher NDVI and TQ when compared with the low-fertility treatment. Although the statistical significance suggests the benefit of increased fertility, specifically in the second year of the study, added inputs over the course of the 2 years may suggest that the value in turfgrass improvement on a plot basis may be outweighed by the economic impacts of such an enhancement. Perhaps carrying on this study into additional years may elucidate the added benefits of higher fertility treatments for bermudagrass response to shaded environments due to a higher input requirement of bermudagrass.

Contrasts for polynomial estimations and entry comparisons. Contrasts were constructed to determine linear and possible quadratic effects in the increasing shade treatments relative to each entry. Because of the unequal increments between shade levels and the use of only three treatments for the regression analysis, determining the dose response for shade levels by entry was inconclusive.

To more readily determine the consistency and stability of each entry across years and response variables, additional contrasts were constructed to compare the mean of an individual entry against the average of all other entries within shade levels on 29 Sept. 2011 and 11 Sept. 2012 (Fig. 2). The ranges in means of the controls ('Celebration', 'TifGrand', and 'Tifway') along with the performance of each entry stabilizes the average and can indicate the size of the effect (negative or positive) each entry contributes to the average within each measurement. Furthermore, the comparison might be used as an indicator of consistency across the dates, which would be considered stability in different environments (Bokmeyer et al., 2009). At a glance, the significance denoted for the individual entries across each shade level within the three response variables can be overwhelming. However, when focusing on each entry independently, 'Celebration' and the South African accessions WIN10F and STIL03 consistently provided higher NDVI, percent TC and TQ in both years when compared with the average of the other entries. Similarly, 'TifGrand' provided higher NDVI, percent TC, and TQ when compared with the average of the other entries in 2011. However, 'TifGrand' did not provide consistency across years and the increases compared with the average of the other entries were not always different. Other accessions such as CoPCCQ, FiPCCQ, Irene, and PCC4 had large effects for single response variables, in 1 year, and/or under a single shade treatment. These accessions, however, showed a lack of consistency when compared with 'Celebration', WIN10F and STIL03.

\section{Conclusions}

Overall, results indicate that there are shade-tolerant genotypes among the bermudagrass materials collected from South Africa. Accessions WIN10F and STIL03 showed consistency in response to shade. These accessions performed similarly to shade-tolerant cultivar Celebration across response variables NDVI, TQ, and percent TC, and also across years. These results were drawn predominantly from $63 \%$ shade treatments where the greatest separation in accessions could be made. While some accessions were able to maintain acceptable TQ in $63 \%$ shade, no entries did so under $80 \%$ shade levels. These materials constitute additional sources of shade hardiness to be used in bermudagrass breeding with the ultimate goal of releasing cultivars with improved performance in low-light environments.

The reduced nitrogen application rate provided similar TQ when compared with the high nitrogen application rate, but significant differences were found between the two treatments in TQ and NDVI in 2012 suggesting the overall effect that increased nitrogen rates are having on the health of the plot. However, the added inputs across the two years suggest a greater economic value in providing these increases for such a low biological effect. In 2011, the low nitrogen rate provided greater TC across the bermudagrass entries beneath $63 \%$ shade relative to higher nitrogen rate $(P \leq 0.05)$, further emphasizing lowered inputs, in this case nitrogen fertility, as a cultural practice for the management of turfgrasses under low-light incidence.

\section{Literature Cited}

Baldwin, C.M., H. Liu, and L.B. McCarty. 2008. Diversity of 42 bermudagrass cultivars in a reduced light environment. International Conference on Turfgrass Science and Management for Sports Fields. Acta Hort. 783:147-158.

Baldwin, C.M., H. Liu, L.B. McCarty, H. Luo, C.E. Wells, and J.E. Toler. 2009. Impacts of altered light spectral quality on warm-season turfgrass growth under greenhouse conditions. Crop Sci. 49:1444-1453.

Beard, J.M. 1973. Turfgrass: Science and culture. Prentice Hall, Englewood Cliffs, NJ.

Bell, G. and K. Danneberger. 1999a. Managing creeping bentgrass in shade. Golf Course Mgt. 67(10):56-60.

Bell, G.E. and T.K. Danneberger. 1999b. Temporal shade on creeping bentgrass turf. Crop Sci. 39:1142-1146.

Bokmeyer, J.M., S.A. Bonos, and W.A. Meyer. 2009. Broad-sense heritability and stability analysis of brown patch resistance in tall fescue. HortScience 44:289-292.

Bunnell, B.T., L.B. McCarty, and W.C. Bridges, Jr. 2005a. Evaluation of three bermudagrass cultivars and meyer Japanese zoysiagrass grown in shade. Intl. Turfgrass Soc. Res. J. 10:826-833.

Bunnell, B.T., L.B. McCarty, and W.C. Bridges. 2005b. 'TifEagle' bermudagrass response to growth factors and mowing height when grown at various hours of sunlight. Crop Sci. 45:575581.

Burton, W.W. 1966. Tifway (Tifton 419) bermudagrass (Reg. No. 7). Crop Sci. 6:93-94.

Carrow, R.N. and A.M. Petrovic. 1992. Effects of traffic on turfgrasses, p. 285-330. In: D.V. Waddington, R.N. Carrow, and R.C. Shearman (eds.). Turfgrass. ASA Monogr. 32. ASA, CSSA, and SSSA, Madison, WI.

DiPaola, J.M. and J.B. Beard. 1992. Physiological effects of temperature stress, p. 231-267. In: D.V. Waddington, R.N. Carrow, and R.C. Shearman (eds.) Turfgrass. ASA Monogr. 32. ASA, CSSA, and SSSA, Madison, WI.

Dudeck, A.E. and C.H. Peacock. 1992. Shade and turfgrass culture, p. 269-284 In: D.V. Waddington, R.N. Carrow, and R.C. Shearman (eds.) Turfgrass. ASA Monogr. 32. ASA, CSSA, and SSSA, Madison, WI.

Gaussoin, R.E., A.A. Baltensperger, and B.N. Coffey. 1988. Response of 32 bermudagrass clones to reduced light intensity. HortScience 23:178-179.

Goss, R.M., J.H. Baird, S.L. Kelm, and R.N. Calhoun. 2002. Trinexapac-ethyl and nitrogen effects on creeping bentgrass grown under reduced light conditions. Crop Sci. $42: 472-479$.

Hanna, W.W. and B. Maw. 2007. Shade-resistant bermudagrass. USGA Green Section Record 45 (2):9 11 .

Hanna, W.W. and S.K. Braman. 2008. Bermudagrass 'ST-5'. U.S. Patent No. PP21017. 19 Aug. 2008.

Hanna, W.W., S.K. Braman, and B.M. Schwartz. 2010. 'ST-5', a shade-tolerant turf bermudagrass. HortScience 45:132-134.

Jiang, Y., R.R. Duncan, and R.N. Carrow. 2004. Assessment of low light tolerance of seashore paspalum and bermudagrass. Crop Sci. 44:587594.

Karcher, D.E. and M.D. Richardson. 2005. Batch analysis of digital images to evaluate turfgrass characteristics. Crop Sci. 45:1536-1539.

McBee, G.G. and E.C. Holt. 1966. Shade tolerance studies on bermudagrass and other turfgrasses. Agron. J. 58:523-525.

Miller, G.L., J.T. Edenfield, and R.T. Nagata. 2005. Growth parameters of Floradwarf and Tifdwarf bermudagrass exposed to various light regimes. Intl. Turfgrass Soc. Res. J. 10:879-884.

NRCS. 2001. Natural Resources Conservation Service. Web Soil Survey. <http://websoilsurvey. sc.egov.usda.gov/>. 
NTEP, National Turfgrass Evaluation Program, accessed 2013. <www.NTEP.org>.

Peacock, C.H. and A.E. Dudeck. 1981. The effects of shade on morphological and physiological parameters of St. Augustinegrass cultivars. Proc. Fourth Intl. Turfgrass Res. Conf., Guelph, Ontario, Canada.

Qian, Y.L. and M.C. Engelke. 1997. Evaluation of zoysiagrass genotypes for shade tolerance. Texas Turfgrass Res. J. 97:1-11.

Qian, Y.L., M.C. Engelke, M.J.V. Foster, and S. M. Reynolds. 1998. Trinexapac-ethyl restricts shoot growth and improves quality of diamond zoysiagrass under shade. HortScience 33:1019-1022.

Richardson, M.D., D.E. Karcher, and L.C. Purcell. 2001. Quantifying turfgrass cover using digital image analysis. Crop Sci. 41:1884-1888.
Riley, R.J. "Cynodon dactylon plant named 'Riley's Super Sport'." U.S. Patent No. PP11,181. 18 Jan. 2000.

Robson, D.S. 1959. A simple method for constructing orthogonal polynomials when the independent variable is unequally spaced. Biometrics 15(2):187-191.

SAS Institute Inc. 2005. SAS Version 9.4. SAS Institute, Cary, NC.

Schmidt, R.E. and R.E. Blaser. 1969. Effect of temperature, light and nitrogen on growth and metabolism of 'Tifgreen' bermudagrass ( $\mathrm{Cyn}$ odon spp.). Crop Sci. 9:5-9.

Sladek, B.S., G.M. Henry, and D.L. Auld. 2009 Evaluation of zoysiagrass genotypes for shade tolerance. HortScience 44:1447-1451.

Stuefer, J. and H. Huber. 1998. Differential effects of light quantity and spectral light quality on growth, morphology and development on two stoloniferous Potentilla species. Oecologia 117:1-8.

Trenholm, L.E. and R.T. Nagata. 2005. Shade tolerance of St. Augtinegrass cultivars. HortTechnology 15:267-272.

Van Huylenbroeck, J.M. and E. Van Bockstaele. 2001. Effects of shading on photosynthetic capacity and growth of turfgrass species. Intl. Turfgrass Soc. Res. J. 9:353359

White, R.H. 2004. Environment and culture affect bermudagrass growth and decline. USGA Greens Section Record. 42(6):21-24.

Wilkinson, J.F. and J.B. Beard. 1975. Anatomical responses of 'Merion' Kentucky bluegrass and 'Pennlawn' red fescue at reduced light intensities. Crop Sci. 15:189-194. 
Supplemental Table 1. Means comparisons for each entry within three shade treatments $(0 \%, 63 \%$, and $80 \%$ ) for normalized difference vegetation index (NDVI), turfgrass cover (TC), and turfgrass quality (TQ) from data collected under a prolonged, shaded environment. The data shown represent 9 weeks after cup-cutter removal on 29 Sept. 2011 at the Lake Wheeler Turfgrass Field Laboratory, Raleigh, NC.

\begin{tabular}{|c|c|c|c|c|c|c|c|c|c|}
\hline \multirow[b]{3}{*}{ Entry (\%) } & \multicolumn{3}{|c|}{ NDVI } & \multicolumn{3}{|c|}{ TC (\%) } & \multicolumn{3}{|c|}{ TQ } \\
\hline & \multicolumn{9}{|c|}{ Shade level } \\
\hline & 0 & 63 & 80 & 0 & 63 & 80 & 0 & 63 & 80 \\
\hline 'Celebration' & 0.756 & 0.675 & 0.646 & 88.3 & 76.0 & 42.8 & 6.0 & 6.7 & 3.7 \\
\hline CoPCCQ & 0.760 & 0.535 & 0.575 & 78.7 & 44.1 & 17.1 & 5.3 & 4.0 & 2.3 \\
\hline FiPCCQ & 0.754 & 0.515 & 0.529 & 86.5 & 42.3 & 14.5 & 6.0 & 4.7 & 1.8 \\
\hline Irene & 0.769 & 0.415 & 0.418 & 78.3 & 21.0 & 7.2 & 7.3 & 3.5 & 1.2 \\
\hline PCC4 & 0.732 & 0.598 & 0.504 & 68.3 & 39.5 & 18.4 & 4.0 & 5.0 & 3.0 \\
\hline PCCT & 0.737 & 0.358 & 0.518 & 79.3 & 22.9 & 12.9 & 5.3 & 4.7 & 1.8 \\
\hline STIL03 & 0.763 & 0.624 & 0.544 & 84.0 & 57.9 & 23.5 & 6.0 & 6.3 & 3.0 \\
\hline 'TifGrand' & 0.766 & 0.519 & 0.550 & 88.7 & 50.3 & 36.8 & 8.0 & 6.3 & 3.0 \\
\hline ‘Tifway’ & 0.732 & 0.435 & 0.377 & 84.4 & 24.6 & 4.7 & 7.0 & 5.0 & 1.3 \\
\hline WIN10F & 0.760 & 0.610 & 0.521 & 84.9 & 57.2 & 28.3 & 6.3 & 6.7 & 3.3 \\
\hline WIN10T & 0.741 & 0.428 & 0.490 & 77.0 & 33.2 & 14.2 & 4.3 & 4.7 & 2.0 \\
\hline WIN17 & 0.769 & 0.475 & 0.432 & 83.4 & 40.6 & 2.7 & 7.0 & 3.8 & 1.0 \\
\hline $\operatorname{LSD}^{\mathrm{z}}$ & 0.077 & 0.077 & 0.077 & 12.6 & 12.6 & 12.6 & 1.1 & 1.1 & 1.1 \\
\hline
\end{tabular}

${ }^{\mathrm{z}}$ Least significant differences based on Fisher's protected LSD $(P=0.05)$.

Supplemental Table 2. Means comparisons for each entry within three shade treatments $(0 \%, 63 \%$, and $80 \%)$ for normalized difference vegetation index (NDVI), turfgrass cover (TC), and turfgrass quality (TQ) from data collected under a prolonged, shaded environment. The data shown represent 9 weeks after cupcutter removal on 11 Sept. 2012 at the Lake Wheeler Turfgrass Field Laboratory, Raleigh, NC.

\begin{tabular}{lccccccccr}
\hline & \multicolumn{3}{c}{ NDVI } & \multicolumn{3}{c}{ TC (\%) } & \multicolumn{3}{c}{ TQ } \\
\cline { 2 - 10 } & \multicolumn{3}{c}{ Shade level } \\
\cline { 2 - 10 } Entry (\%) & 0 & 63 & 80 & 0 & 63 & 80 & 0 & 63 & 80 \\
'Celebration' & 0.679 & 0.663 & 0.570 & 57.8 & 59.3 & 53.6 & 6.5 & 6.7 & 4.3 \\
CoPCCQ & 0.599 & 0.550 & 0.555 & 58.2 & 44.1 & 14.2 & 5.3 & 4.3 & 1.7 \\
FiPCCQ & 0.644 & 0.616 & 0.540 & 64.3 & 58.4 & 26.6 & 6.5 & 5.0 & 2.2 \\
Irene & 0.655 & 0.582 & 0.564 & 63.7 & 42.4 & 34.2 & 7.3 & 4.7 & 2.3 \\
PCC4 & 0.549 & 0.537 & 0.522 & 43.6 & 46.0 & 23.2 & 4.0 & 4.7 & 2.2 \\
PCCT & 0.618 & 0.545 & 0.484 & 66.8 & 44.5 & 19.3 & 5.5 & 4.3 & 1.7 \\
STIL03 & 0.663 & 0.635 & 0.540 & 57.3 & 66.4 & 40.9 & 6.3 & 6.7 & 3.7 \\
'TifGrand' & 0.668 & 0.562 & 0.452 & 72.5 & 40.9 & 32.5 & 8.0 & 6.0 & 2.8 \\
'Tifway' & 0.624 & 0.459 & 0.476 & 52.1 & 31.6 & 25.8 & 7.5 & 4.3 & 2.3 \\
WIN10F & 0.679 & 0.644 & 0.603 & 68.2 & 62.9 & 52.8 & 7.3 & 7.0 & 4.3 \\
WIN10T & 0.580 & 0.534 & 0.460 & 64.5 & 36.7 & 19.8 & 5.0 & 4.2 & 1.3 \\
WIN17 & 0.666 & 0.577 & 0.528 & 67.5 & 56.8 & 25.0 & 7.2 & 5.0 & 2.0 \\
LSD & 0.049 & 0.049 & 0.049 & 18.3 & 18.3 & 18.3 & 0.9 & 0.9 & 0.9 \\
\hline
\end{tabular}

${ }^{\mathrm{z}}$ Least significant differences based on Fisher's protected LSD $(P=0.05)$. 